\title{
Radiation-induced chromosome damage in human lymphocytes
}

\author{
D. C. LLOYD AND G. W. DOLPHIN \\ From the National Radiological Protection Board, Harwell, Didcot, Oxon. OX11 ORQ
}

\begin{abstract}
Analysis for chromosome aberrations in human peripheral blood lymphocytes has been developed as an indicator of dose from ionising radiation. This paper outlines the mechanism of production of aberrations, the technique for their analysis and the dose-effect relationships for various types of radiation. During the past ten years the National Radiological Protection Board has developed a service for the UK in which estimates of dose from chromosome aberration analysis are made on people known or suspected of being accidentally over-exposed. This service can provide estimates where no physical dosemeter was worn and is frequently able to resolve anomalous or disputed data from routine film badges. Several problems in the interpretation of chromosome aberration yields are reviewed. These include the effects of partial body irradiation and the response to variations in dose rate and the intermittent nature of some exposures. The dosimetry service is supported by a research programme which includes surveys of groups of patients irradiated for medical purposes. Two surveys are described. In the first, lymphocyte aberrations were examined in rheumatoid arthritis patients receiving intra-articular injections of colloidal radiogold or radioyttrium. A proportion of the nuclide leaked from the joint into the regional lymphatic system. In the second survey a comparison was made between the cytogenetic and physical estimates of whole body dose in patients receiving iodine 131 for thyroid carcinoma.
\end{abstract}

In the early part of this century observations on plant cells showed that ionising radiation produces chromosome damage. The first quantitative studies using Tradescantia microspores were published by Sax in 1938. During the ensuing two decades Sax and other workers carried out many experimental stiudies with plants, especially with species of Tradescantia, to examine how the amount of chromosome damage changed with various physical and biological factors. These included dose, dose rate, the quality of radiation, irradiation at different stages of the cell cycle, the temperature during irradiation and the presence of oxygen. This early work was reviewed comprehensively by Giles in 1954.

By 1946 the studies had progressed sufficiently for Lea to propose a theory of chromosome breaks suggesting that they were caused by several ionisations produced by one ionising particle as it passed through the chromosome or chromatid. Improvements in the techniques of cell culture and slide preparation enabled the examination of human cells

Received for publication 1 June 1977

Accepted for publication 21 June 1977 and by the mid-1950s the identification of the 46 chromosomes. However, the main breakthrough occurred in 1960 when Moorhead et al. published a method for stimulating peripheral blood lymphocytes to divide in culture. With the availability of lymphocytes and the ease with which they could be cultured and dispensed onto slides these cells became the material of choice for many human chromosome studies. Abnormalities in both the number and structure of chromosomes then became readily detectable although for the latter initially only gross modifications such as breaks and large exchanges of material between chromosomes could be easily identified.

During the last five years significant advances have been made in chromosome staining which enable more subtle rearrangements of the chromosome material to be seen. These techniques, $G$ banding (Sumner et al., 1971), C banding (Sumner, 1972), R banding (Dutrillaux and Lejeune, 1971) and harlequin staining (Perry and Wolff, 1974) have not yet made a practical contribution to cytogenetic dosimetry, but they do open up the possibility of quantitative work with stable aberrations.

It is now appreciated that some structural 
aberrations are suitable for the screening of mutagenic and therefore potentially carcinogenic chemicals to which people may be exposed at work or in the environment (Perry and Evans, 1975). However this paper is confined to a review of the effects of ionising radiation on chromosomes in the peripheral blood lymphocytes.

\section{Types of chromosome aberrations}

Both chromosome and chromatid type aberrations are observed at the first post-irradiation metaphase. Chromosome aberrations are produced after irradiation during the $G_{0}$ or early $G_{1}$ stages of the cell cycle so that damage is duplicated in the $S$ stage and is expressed at metaphase as symmetrical damage involving both chromatids. Chromatid aberrations are produced by irradiation after the chromosome has split into two chromatids in the $S$ and $G_{2}$ stages and are not symmetrical. Such a break in one chromatid may be replicated in the next $S$ stage if the cell is able to pass through the first division into the second cycle. The symmetrical aberrations produced from chromatid damage in this way are known as derived chromosome aberrations.

In irradiated tissues where cell division is constantly taking place both chromosome and chromatid aberrations are observed. The relative numbers found depend on the time interval between irradiation and biopsy as well as on the sensitivity of the chromosomes during the various stages of the cycle. A great advantage of studying aberrations in lymphocytes is that for all practical purposes these cells are in the $\mathrm{G}_{0}$ stage in vivo so that only chromosome damage is induced. Thus in the present review we propose to consider only chromosome-type damage and the reader is referred to Savage (1976) for more information about chromatid aberrations.

Figures 1 and 2 show how chromosome-type aberrations are formed by intra- and inter-changes respectively. In the $G_{0}$ stage the chromosome material consists of a single strand of DNA which may be broken by ionisations produced by the passage of a charged particle through or near to the chromosome. The charged particles generated by the absorption of $x$ - or $\gamma$-radiation are electrons which have a relatively low density of ionisation along their tracks, that is, a low linear energy transfer (LET). Heavier particles such as alphas and protons associated with neutron absorption have a high LET and may produce more aberrations per unit distance along the track than electrons. In the figures the break points in the chromosomes are indicated by arrows but this does not necessarily mean that each

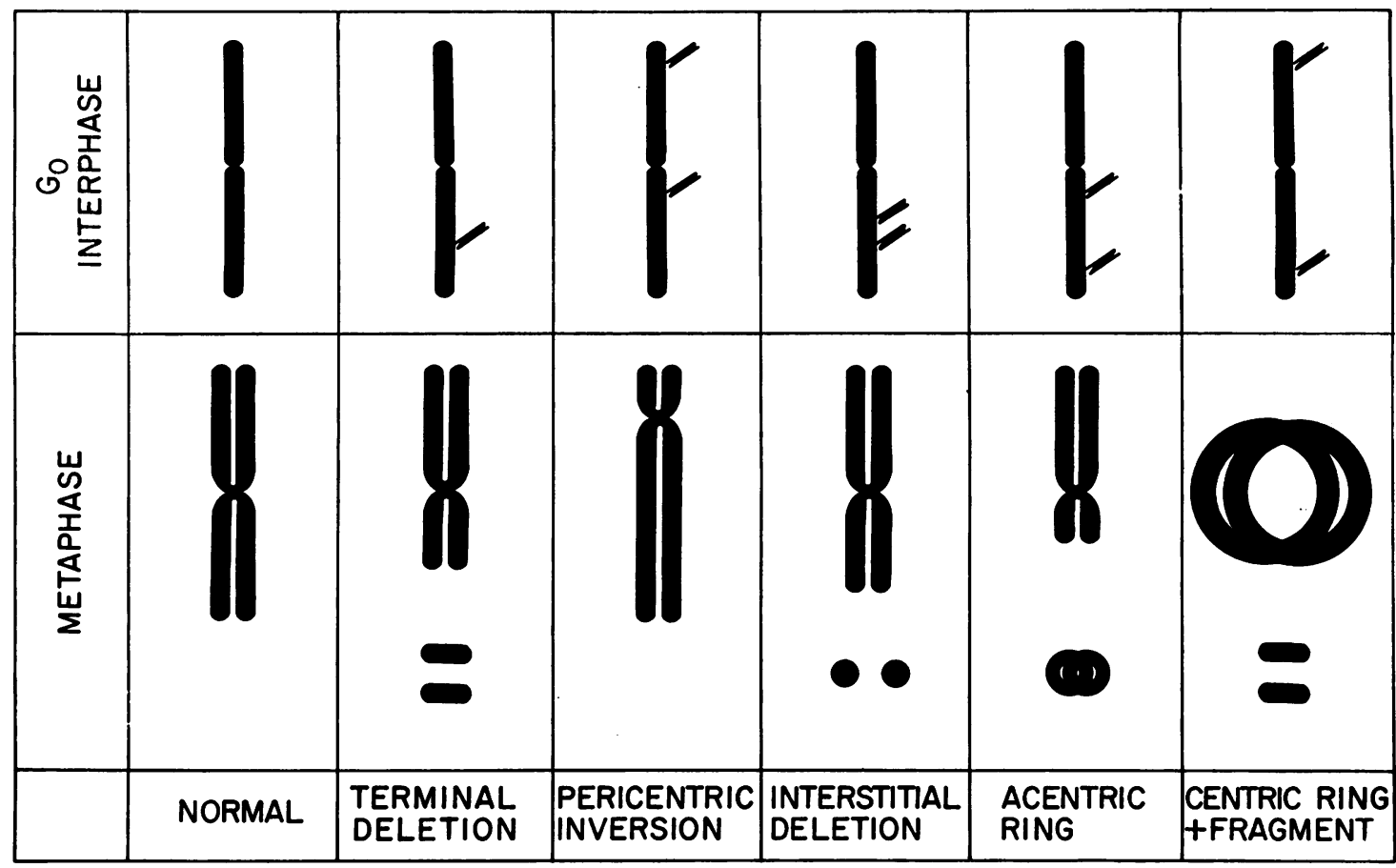

Fig. 1 Chromosome type aberrations-intrachanges 


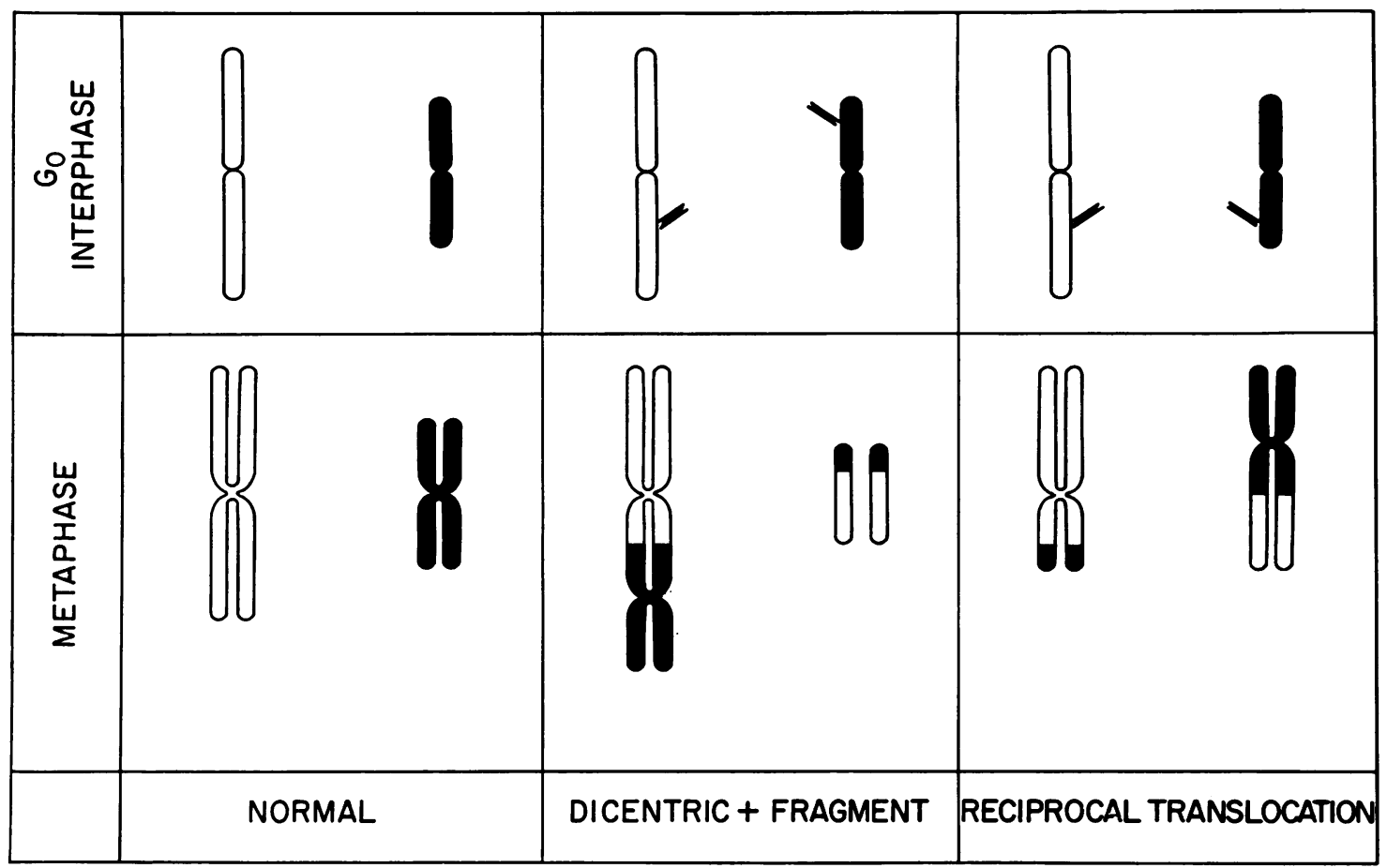

Fig. 2 Chromosome type aberrations-interchanges

break is produced by a different particle track. The long strands of DNA are probably intertwined so that there is a possibility of a single track, particularly a densely ionising one, causing breaks in two or more chromosomes or in the same chromosome at different places.

Chromosome aberrations may be divided into two categories: stable aberrations which can pass through repeated divisions, and unstable aberrations in which the chromosome material does not divide equally between daughter cells so that both cell lines eventually die.

\section{STABLE ABERRATIONS}

The two aberrations illustrated in Figures 1 and 2 are a pericentric inversion and a translocation. Stable aberrations have not as yet been used in biological dosimetry because many cannot be detected in conventionally stained preparations. Although more can be observed with the new differentially stained preparations, scoring is a relatively slow procedure more suited to the automated systems of cell finding and karyotype analysis which are under development (Mayall, 1976).
UNSTABLE ABERRATIONS

Chromosome material containing essential genetic information may be lost when cells with unstable aberrations attempt to divide. For example, acentric pieces do not attach to the mitotic spindle and therefore fail to divide equally between the daughter cells. Dicentrics frequently form anaphase bridges when the centromeres are pulled towards opposite poles.

Unstable aberrations are particularly valuable in the analysis of radiation-induced damage as they are easily observed at metaphase. They are usually classified into three types which are shown in Figs. 1 and 2, and in a metaphase spread in Fig. 3.

\section{Dicentric plus fragment}

These arise from a break in each of two chromosomes which rejoin incorrectly to form a structure with two centromeres plus an acentric fragment. Occasionally, for example following a high dose, more than two chromosomes may be involved so that a polycentric aberration is produced. Examples of a tricentric and a quadricentric are also contained in Fig. 3. The dicentric and its multiple forms are considered to be the key aberrations for determining 


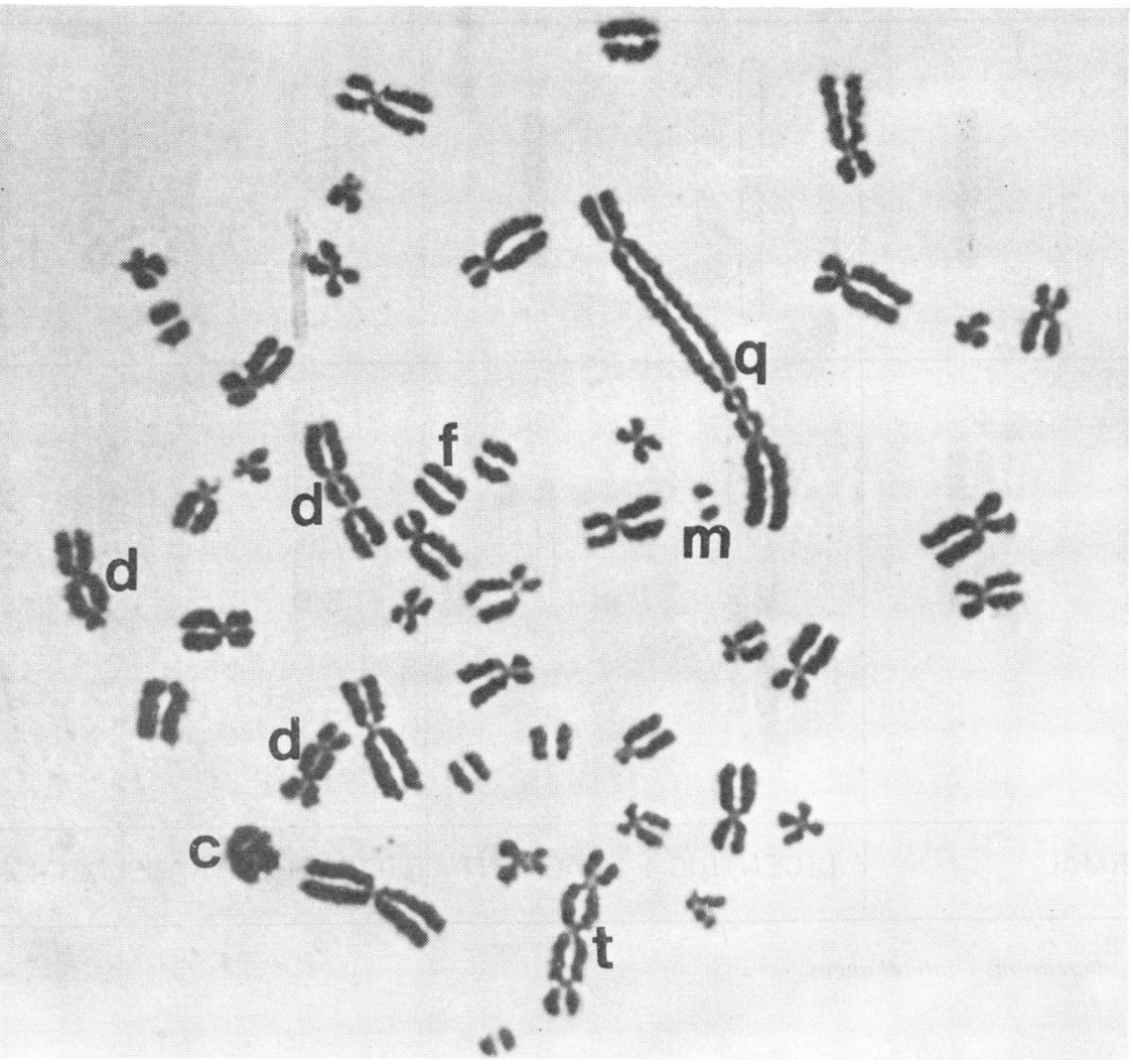

Fig. 3 A metaphase spread from a human lymphocyte exhibiting most of the chromosome type aberrations $\mathrm{d}=$ dicentric; $\mathrm{t}=$ tricentric;

$\mathrm{q}=$ quadricentric; $\mathrm{f}=$ fragment (terminal deletion);

$\mathrm{m}=$ minute (interstitial deletion); $\mathrm{c}=$ centric ring. Not all aberrations have been labelled in this figure

radiation dose because they have a low background frequency in lymphocytes from unirradiated subjects ( 1 in $\sim 3000$ cells). The presence of two or more centromeres usually gives them a very distinctive appearance, and the fragment associated with dicentric formation serves as an additional confirmation.

Centric ring plus fragment

When two breaks occur in the same chromosome but on either side of the centromere, incorrect rejoining results in the formation of a ring possessing the centromere and an acentric fragment. Like the dicentric, this aberration can be formed by one or two tracks. The similarity in the formation of the dicentric and the ring leads some observers to combine them when reporting aberration yields.

\section{Acentric}

Three types of aberrations are grouped under this classification; terminal deletions, interstitial deletions and acentric rings. Each may be produced separately or in association with dicentrics and centric rings. It is necessary to group these together because a clear distinction cannot be made between them. For example, a small acentric ring approaches the size and shape of an interstitial deletion and both can be confused with some terminal deletions. The terminal deletion in principle could be produced by the passage of a single ionising track through a chromosome but the others involve two breaks. The high incidence of acentric aberrations in unirradiated subjects ( 1 in $\sim 300$ cells) and the possibility that very small examples may be overlooked means that the value of acentrics in dosimetry is somewhat limited.

\section{Lymphocyte culture techniques}

In order to observe aberrations with the light microscope it is necessary to examine chromosomes in the metaphase stage of the cell cycle. For many types of cells and certainly for peripheral blood lymphocytes the cells must be cultured through to metaphase. Most lymphocyte culture techniques now in use are based on the method of Moorhead 
et al. (1960). The techniques used in the National Radiological Protection Board (NRPB) laboratory have been described in detail by Purrott and Lloyd (1972). Essentially the method involves stimulating the lymphocytes from the $\mathrm{G}_{0}$ stage into the cell cycle with a mitogen such as phytohaemagglutinin (PHA) followed by incubation at $37^{\circ} \mathrm{C}$ for $48-52$ hours in a mixture of a defined medium and natural serum. Three basic methods have been developed. The macro technique utilises serum from the patient's own blood and hence a sample of about $20 \mathrm{ml}$ is required. For mini cultures, which are used routinely in our laboratory, the lymphocytes are separated from $1 \mathrm{ml}$ aliquots of blood by gentle centrifugation. The presence of PHA at this stage assists the separation because of its agglutinating properties. In the micro technique $0.25 \mathrm{ml}$ of whole blood, which may be obtained from a fingerprick, is cultured.

\section{Lymphocytes in humans}

The mean lifetime of lymphocytes in the circulation has been calculated by measuring the rate of build-up in peripheral blood of lymphocytes labelled with aberrations induced by extracorporeal irradiation in an arteriovenous shunt. Sharpe et al. (1968) found that these lymphocytes disappeared rapidly, presumably into the extravascular pool, with a mean residence time in the peripheral blood of about five minutes.

From these measurements the total mass of lymphocytes in the body was estimated to be about $1000 \mathrm{~g}$ with $3 \mathrm{~g}$ circulating in the peripheral blood. The mass of lymphocytes in the body, given in ICRP Publication 23 (International Commission on Radiological Protection, 1975), is $1500 \mathrm{~g}$ for men and $1200 \mathrm{~g}$ for women. Hence there is good agreement between the results from the labelled lymphocyte method and those from other methods.

The turnover of lymphocytes in the body has been estimated from the disappearance of lymphocytes with chromosome aberrations from the peripheral blood after irradiation. Norman et al. (1966) studied 25 women treated with radiation for carcinoma of the cervix and found a survival time for lymphocytes with aberrations of $530 \pm 64$ days. In patients treated with $x$-rays for ankylosing spondylitis, Buckton et al. (1967) found a mean-life of 1574 days. At NRPB, data accumulated from a case of accidental overexposure gave a value of about 800 days (Dolphin $e t$ al., 1973). However some lymphocytes have a very long life-span and this is illustrated by the presence of aberrations in survivors 20 years after the Japanese atomic bombings (Bloom et al., 1966). This long turn-over time means that the aberration yield will tend to integrate the radiation dose accumulated over a long period. Nevertheless there is still much uncertainty about the life-span of the lymphocyte and how it depends on the health of the individual person.

Recent research has demonstrated the existence of several subpopulations of lymphocytes and the two main types are thymus-dependent $T$ cells and nonthymus-dependent B cells (Greaves et al., 1974). Lymphocytes stimulated by PHA are presumed to be T-type and consequently most of the work reported on chromosome aberrations applies only to $\mathrm{T}$ cells. In a healthy adult about $60 \%$ of the peripheral blood lymphocytes are T cells. Prosser (1976) has shown that $B$ cells are more sensitive to radiation than $T$ cells in experiments in which he observed the loss of viability, as measured by trypan blue exclusion tests in non-dividing cells. In patients treated with $x$-rays, Blomgren et al. (1974) found that the percentage of presumed B cells in the total lymphocyte population was halved after treatment. This is in agreement with the observation of Prosser that in in vitro experiments B cells show a higher radiosensitivity. However, not all experimenters agree, and more research is required to establish the kinetics of the lymphocyte response after the whole or part of the body has been irradiated.

The rapid fall in the total lymphocyte count in the peripheral blood after whole body irradiation (Vodopick and Andrews, 1974) has not been explained. It is probably not due to the intrinsic radiosensitivity of the cell, for Lloyd et al. (1975a) showed in vitro that the survival of lymphocytes was similar to that of other types of irradiated human cells when cultured and tested for their colonyforming ability. Thus in vivo the fall in the lymphocyte count is probably not due to cell death but may reflect an enhanced migration of cells out of the vasculature and into other tissues.

\section{Radiation-induced aberration yields}

Data from animal experiments (Clemenger and Scott, 1971) and from humans (Buckton et al., 1971) have established that the aberration yield in lymphocytes following a uniform whole body irradiation is similar to that obtained when blood samples are irradiated to the same dose level in vitro. Therefore it is possible to construct in vitro curves relating radiation dose to chromosome aberration yield and to use these curves to estimate dose by analysing blood samples from people accidentally overexposed. The most important in vitro curves for radiological protection purposes have now been established in the NRPB laboratory (Lloyd et al., $1975 \mathrm{a}, 1976 \mathrm{a})$. These are for $250 \mathrm{kV} x$-rays, cobalt 60 $\gamma$-radiation and neutrons (Fig. 4). 


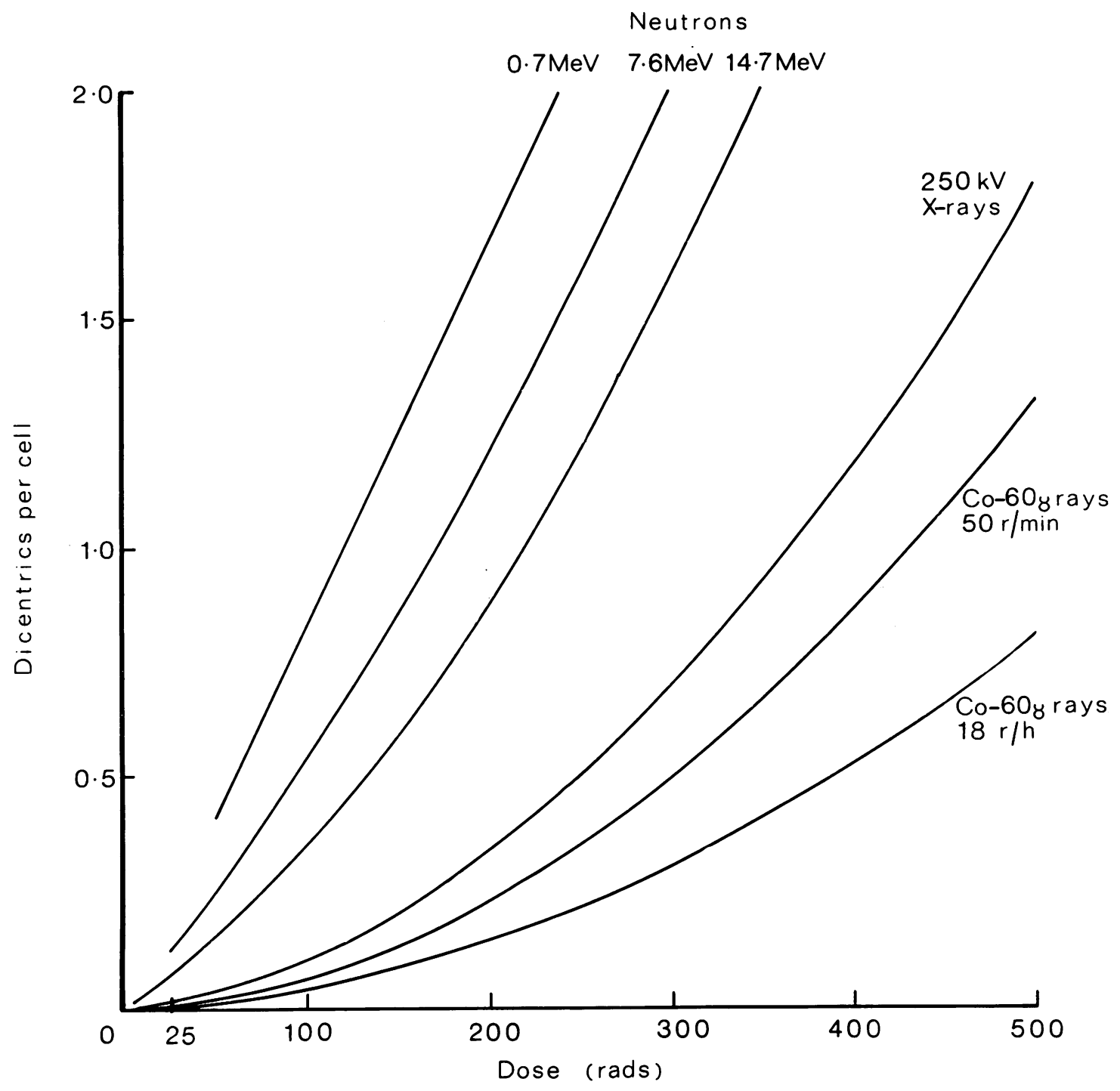

Fig. 4 In vitro dose response curves for dicentric aberration yields plotted against dose for five qualities of radiation.

Data on aberration yield (Y) obtained in this laboratory have been shown to fit a mathematical function of the form: $\mathbf{Y}=\alpha \mathbf{D}+\beta \mathbf{D}^{2}$, where $\mathbf{D}$ is the dose in rads and $\alpha$ and $\beta$ are constants. A physical representation of this function is the production of some aberrations by single ionising tracks so that the yield is proportional to the dose $(\alpha \mathrm{D})$ and of other aberrations by two separate tracks with yields proportional to the square of the dose $\left(\beta D^{2}\right)$. The formation of dicentric aberrations clearly requires two lesions which may be produced by one or two tracks whereas some acentrics may be formed by one lesion and others by two. With more densely ionising radiation there is an increased likelihood that two breaks are produced by a single ionising track and for fission spectrum neutrons this results in a relationship between yield and dose which is entirely linear $(Y=\alpha D)$. The values of the coefficients, $\alpha$ and $\beta$, obtained in this laboratory for various qualities of radiation are given in Table 1 . 
Table 1 Values of the coefficients $a$ and $\beta$ in the equation $Y=a D+\beta D^{2}$ for dicentric and acentric aberrations and $R B E$ values relative to ${ }^{60} \mathrm{Co} \gamma$-radiation at $50 \mathrm{rads} / \mathrm{min}$

\begin{tabular}{|c|c|c|c|c|c|c|}
\hline Radiation type & $\begin{array}{l}\text { Aberration } \\
\text { type }\end{array}$ & $\begin{array}{l}\text { Coefficient a } \\
\pm \text { S.E. } \times 10^{-4}\end{array}$ & $\begin{array}{l}\text { Coefficient } \beta \\
\pm \text { S.E. } \times 10^{-6}\end{array}$ & 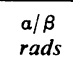 & $\begin{array}{l}\text { RBE at } \\
\text { low doses }\end{array}$ & $\begin{array}{l}\text { RBE at } 200 \text { rads } \\
\gamma \text { equivalent }\end{array}$ \\
\hline Fission spectrum neutrons $\overline{\mathrm{E}}=0.7 \mathrm{MeV}$ & $\begin{array}{l}\text { Dicentrics } \\
\text { Acentrics } \\
\text { Total }\end{array}$ & $\begin{array}{r}83.5 \pm 1.0 \\
85.4 \pm 3.6 \\
178.9 \pm 4.6\end{array}$ & - & - & 47 & $8 \cdot 0$ \\
\hline D-Be cyclotron neutrons $\bar{E}=7.6 \mathrm{MeV}$ & $\begin{array}{l}\text { Dicentrics } \\
\text { Acentrics } \\
\text { Total }\end{array}$ & $\begin{array}{l}47 \cdot 8 \pm 3 \cdot 3 \\
35 \cdot 9 \pm 4 \cdot 9 \\
87 \cdot 8 \pm 7 \cdot 7\end{array}$ & $\begin{array}{l}6 \cdot 4 \pm 2.0 \\
3 \cdot 8 \pm 2 \cdot 7 \\
9 \cdot 5 \pm 4 \cdot 3\end{array}$ & $\begin{array}{l}748 \\
951 \\
922\end{array}$ & 23 & $4 \cdot 1$ \\
\hline D-T generator neutrons $\bar{E}=14.7 \mathrm{MeV}$ & $\begin{array}{l}\text { Dicentrics } \\
\text { Acentrics } \\
\text { Total }\end{array}$ & $\begin{array}{l}26 \cdot 2 \pm 4 \cdot 0 \\
20 \cdot 7 \pm 3 \cdot 6 \\
49 \cdot 3 \pm 6 \cdot 2\end{array}$ & $\begin{array}{r}8 \cdot 8 \pm 2 \cdot 8 \\
6 \cdot 2 \pm 2 \cdot 4 \\
14 \cdot 7 \pm 4 \cdot 3\end{array}$ & $\begin{array}{l}296 \\
335 \\
335\end{array}$ & 13 & $2 \cdot 7$ \\
\hline $250 \mathrm{kV} x$-rays at $100 \mathrm{rads} / \mathrm{min}$ & $\begin{array}{l}\text { Dicentrics } \\
\text { Acentrics } \\
\text { Total }\end{array}$ & $\begin{array}{l}4.8 \pm 0.5 \\
3.3 \pm 1.2 \\
9.4 \pm 1.7\end{array}$ & $\begin{array}{l}6.2 \pm 0.3 \\
3.4 \pm 0.6 \\
9.6 \pm 0.9\end{array}$ & $\begin{array}{r}77 \\
101 \\
99\end{array}$ & $2 \cdot 5$ & $1 \cdot 1$ \\
\hline${ }^{\circ 0} \mathrm{Cobalt} \gamma$-rays at $50 \mathrm{rads} / \mathrm{min}$ & $\begin{array}{l}\text { Dicentrics } \\
\text { Acentrics } \\
\text { Total }\end{array}$ & $\begin{array}{l}1.6 \pm 0.3 \\
2.3 \pm 0.7 \\
3.8 \pm 0.9\end{array}$ & $\begin{array}{l}5.0 \pm 0.2 \\
3.9 \pm 0.4 \\
9 \cdot 4 \pm 0.5\end{array}$ & $\begin{array}{l}31 \\
59 \\
40\end{array}$ & 1 & 1 \\
\hline${ }^{60} \mathrm{Cobalt} \gamma$-rays at $18 \mathrm{rads} / \mathrm{h}$ & $\begin{array}{l}\text { Dicentrics } \\
\text { Acentrics } \\
\text { Total }\end{array}$ & $\begin{array}{l}1.8 \pm 0.8 \\
2.6 \pm 0.7 \\
4.8 \pm 1.6\end{array}$ & $\begin{array}{l}2.9 \pm 0.5 \\
1.4 \pm 0.3 \\
4 \cdot 4 \pm 0.8\end{array}$ & $\begin{array}{r}60 \\
194 \\
109\end{array}$ & $\sim 1$ & 0.7 \\
\hline
\end{tabular}

One property of the quadratic function is that the quotient $\alpha / \beta$ has the dimension of rads and is the dose at which the number of aberrations produced by single and two-track events is equal. These values are shown in column 5 of Table 1 , and below this dose the majority of aberrations will be produced by single tracks. As these lesions must be produced almost simultaneously when the ionising particle traverses the nucleus, aberrations associated with the linear term are independent of the effects of dose rate or fractionation. This is illustrated in Table 1 where for the high and low dose rate cobalt 60 $\gamma$-radiation the two $\alpha$ coefficients are approximately equal while the $\beta$ terms are not. As the majority of aberrations result from the linear term at low doses the two $\gamma$-radiation curves, in Fig. 4, are indistinguishable below about 20 rads. At very low doses such as those accumulated by radiation workers operating within permitted dose limits, the relative biological effectiveness (RBE) of the radiations may be expressed as the ratios of the $\alpha$ coefficients. These are given in column 6 of Table 1 for the total aberration yields and it is interesting to note that $250 \mathrm{kV} x$-rays have an RBE of 2.5 with respect to $\gamma$-rays at approximately the same dose rate. Another interesting feature of this column is that RBE values for neutrons are much higher than the quality factors for such radiations used in radiological protection. However the biological end-point of concern in radiological protection is cancer induction and $R B E$ values derived from visible chromosome damage are not necessarily applicable. At higher doses, RBE decreases and in column 7 of Table 1 values are shown at a damage level equivalent to 200 rads of $\gamma$-rays, which are more appropriate for the doses usually associated with single dose fractions used in radiotherapy.

The relative frequency with which chromosome aberrations are observed in irradiated lymphocytes depends on the dose and the type of radiation. At low doses of low LET radiation, represented by the first four doses of $250 \mathrm{kV} x$-rays in Table 2, centric rings are on average about $9 \%$ of the dicentrics

Table 2 The number of centric rings and acentrics expressed as a percentage of the observed dicentrics for two dose levels of low LET radiation and for fission neutrons

\begin{tabular}{|c|c|c|c|c|}
\hline \multirow{2}{*}{$\begin{array}{l}\text { Radiation } \\
\text { type }\end{array}$} & \multirow{2}{*}{$\begin{array}{l}\text { Dose } \\
\text { (rads) }\end{array}$} & \multirow{2}{*}{$\begin{array}{l}\text { Dicentrics/ } \\
\text { cell }\end{array}$} & \multicolumn{2}{|c|}{ Percentage of dicentrics } \\
\hline & & & $\begin{array}{l}\text { Centric } \\
\text { rings }\end{array}$ & Acentrics \\
\hline \multirow[t]{2}{*}{$\begin{array}{c}\text { Low dose } \\
250 \mathrm{kV} \\
x \text {-rays }\end{array}$} & $\begin{array}{r}5 \\
10 \\
25 \\
50\end{array}$ & $\begin{array}{l}0.0027 \\
0.006 \\
0.014 \\
0.042\end{array}$ & $\begin{array}{r}22 \\
11 \\
12 \\
5\end{array}$ & $\begin{array}{r}500 \\
225 \\
128 \\
63\end{array}$ \\
\hline & & mean & 9 & 122 \\
\hline \multirow[t]{2}{*}{$\begin{array}{c}\text { High dose } \\
250 \mathrm{kV} \\
x \text {-rays }\end{array}$} & $\begin{array}{l}300 \\
400 \\
500\end{array}$ & $\begin{array}{l}0 \cdot 75 \\
1 \cdot 31 \\
2 \cdot 24\end{array}$ & $\begin{array}{l}5 \\
5 \\
4\end{array}$ & $\begin{array}{l}70 \\
54 \\
50\end{array}$ \\
\hline & & mean & 5 & 57 \\
\hline \multirow[t]{2}{*}{$\begin{array}{l}\text { Fission } \\
\text { neutrons }\end{array}$} & $\begin{array}{r}50 \\
75 \\
100 \\
150\end{array}$ & $\begin{array}{l}0.41 \\
0.60 \\
0.82 \\
1.27\end{array}$ & $\begin{array}{r}8 \\
6 \\
18 \\
9\end{array}$ & $\begin{array}{r}93 \\
104 \\
92 \\
103\end{array}$ \\
\hline & & mean & 10 & 96 \\
\hline
\end{tabular}


while the value for the acentrics is $122 \%$. At these doses most of the aberrations are considered to be produced by a single track. At the higher doses of $x$-rays, 300 to 500 rads, where dicentrics are produced mainly by two tracks, the percentage of centric rings has halved to $5 \%$ and acentrics are $57 \%$ of the dicentrics. For high LET radiation where all aberrations are considered to be produced by single tracks, centric rings are $10 \%$ and acentrics $96 \%$ of the dicentrics. The similarity of the aberration distribution for low doses of low LET radiation and high LET radiation where single tracks are involved indicates that single tracks produce centric rings and acentrics more effectively than dicentrics. Expressed in another way, single tracks may produce intrachanges involving both one and two breaks more frequently than interchanges.

During the last ten years most scientists concerned with radiological protection have accepted that the measurement of chromosome aberration yields in peripheral blood lymphocytes is the best available basis for biological dosimetry. This technique was developed with a major radiation accident, such as a criticality excursion, in mind but accidents of this type seldom occur and the expense of maintaining a biological dosimetry system could not be justified on these grounds alone. The cytogenetics laboratory of NRPB now fulfils a different role from that envisaged when it was established in 1967. Since then, blood samples from 272 known or suspected cases of overexposure mainly to low LET radiation have been examined. The majority of incidents have involved industrial radiographers and all have been described in annual reports from the laboratory (Purrott $e t$ al., 1972, 1973, 1974, 1975, 1976; Lloyd et al., 1977b). This biological dosimetry service is maintained as an addition to the routine personal monitoring by film badges and is used when a known or suspected overexposure to penetrating radiation has occurred and when the cytogenetic data may usefully supplement physical dosimetry.

The 272 cases where blood samples have been obtained for biological dosimetry may be divided into four categories as shown in Table 3. About $70 \%$ fall into category $A$ in which there is doubt that the film badge has recorded a reasonable whole body dose for one or more reasons such as inadvertent or wilful exposure while not being worn, non-uniform irradiation, or film blackening caused by heat or chemical contamination. In these cases it is important to resolve the doubt because the future employment of the radiation worker may be at stake and considerable personal anxiety may be involved. In category B exposure is known or thought to have occurred but no film badge was worn and here chromosome aberration analysis is the only available
Table 3 The distribution of investigations between the four categories

\begin{tabular}{lr}
\hline Category & Totals \\
\hline $\begin{array}{l}\text { A. Possible non-uniform exposure in which the relationship } \\
\text { between dose to the film badge and to the body is } \\
\text { uncertain }\end{array}$ & 193 \\
B. Suspected over-exposure to persons not wearing a \\
$\begin{array}{l}\text { dosemeter } \\
\text { C. Over-exposure where satisfactory estimates of the whole } \\
\text { body dose can be made from physical measurements }\end{array}$ \\
$\begin{array}{l}\text { D. Chronic internal and external exposure } \\
\end{array}$ & $\frac{56}{272}$ \\
\hline
\end{tabular}

method for dose assessment. Occasionally, welldefined accidental over-exposures occur which can be reconstructed and the whole body dose estimated from the film badge reading and the position of the worker relative to the radiation source (category $\mathrm{C}$ ). In these reconstructed incidents it is possible to compare the physical and biological dose estimates and on the few occasions when this has been possibic, good agreement has been observed. In the final category, D, blood samples are sometimes obtained from persons acutely or chronically exposed to radioactive materials. However, in most of these cases it is not possible to make an estimate of the equivalent whole body dose. The majority of cases result from industrial applications of radiation (Table 4), particularly the use of iridium 192 for non-destructive testing. The remaining cases are about equally divided between the major nuclear organisations and research, education and health service institutions. Table 4 shows the numbers of cases in which no dicentric aberrations were found indicating that the doses received were zero or trivial. Of the 100 positive cases recorded the dicentric yields generally indicated small exposures; 74 with equivalent whole body dose estimates below 30 rads. There have been two moderately large overdoses (90 and 200 rads) in the UK since 1967, both involving industrial radiographic sources (Lloyd et al., 1973a; Harrison et al., 1974). In both cases partial body exposures were involved resulting in

Table 4 The origin of cases referred to the laboratory and the number in which no dicentric aberrations were found

\begin{tabular}{lcc}
\hline Case origins & No. of cases & $\begin{array}{l}\text { No. of zero dose } \\
\text { estimates }\end{array}$ \\
\hline Industrial radiography & $183(67 \%)$ & 121 \\
Major nuclear organisations* & $48(18 \%)$ & 26 \\
Research, Education and & $41(15 \%)$ & 25 \\
$\quad$ Health Service Institutions & 272 & 172 \\
Totals & & \\
\hline
\end{tabular}

*e.g. United Kingdom Atomic Energy Authority; British Nuclear Fuels Ltd.; Central Electricity Generating Board; The Radiochemical Centre. 
localised burns severe enough to require surgery for removal of necrotic tissues.

Except at low doses of low LET radiation the aberration yield is not linearly related to the radiation. Consequently the dose estimate from the chromosome aberration yield is expressed as the equivalent whole body dose which is defined as that uniform dose to the whole body which would induce the observed aberration yield (Dolphin, 1969). For most blood samples received by the laboratory 500 lymphocytes are scored which involves about two days' work by a skilled technician. The equivalent whole body dose estimated from the number of dicentrics observed in 500 cells is given in Table 5 for cobalt $60 \gamma$-radiation and $250 \mathrm{kV} x$-rays. These data were obtained in the NRPB laboratory and may not be applicable in other laboratories using different scoring criteria.

The NRPB operates a service based on blood samples sent through the post. A kit containing a $\gamma$-sterilised lithium heparin specimen tube, an instruction sheet and a self-addressed padded envelope (Jiffy bag) is sent to the doctor who is asked to return the sample by First Class post. Because of the longevity of lymphocytes in the body, delays of possibly several weeks before sampling may be tolerated without detriment to the dose estimate. This is important for it is possible that the occurrence of an over-exposure may not be appreciated until the film badge is processed up to four weeks later. Further delays are inevitable while the data from the film are considered, the man questioned, and a blood sample kit sent out from the laboratory.

Once a sample is taken some delay in its transit can also be tolerated. This has enabled samples despatched by air from outside Europe to be successfully processed in the laboratory. In a recent experiment (Purrott et al., 1974) postal delays of up to six days were simulated with no effect on the eventual dose estimate. Once received in the laboratory, lymphocytes are cultured for $\mathbf{4 8}$ hours by the mini method outlined earlier.

Table 5 The equivalent whole body dose from exposure to cobalt $60 \gamma$-rays or $250 \mathrm{kV} \mathrm{x}$-rays estimated from the number of dicentrics observed per 500 cells

\begin{tabular}{lll}
\hline $\begin{array}{l}\text { Dicentrics } \\
\text { in } \\
500 \text { cells }\end{array}$ & $\begin{array}{l}\text { Equivalent whole body dose } \\
(95 \% \text { confidence limits })\end{array}$ \\
& rads \\
\cline { 2 - 3 } & Cobalt 60 y-rays & 250 kV x-rays \\
\hline 0 & $0(26,-)$ & $0(13,-)$ \\
1 & $10(34,1)$ & $4(19,1)$ \\
2 & $17(40,2)$ & $8(23,1)$ \\
3 & $22(46,6)$ & $11(27,2)$ \\
5 & $27(50,10)$ & $14(31,4)$ \\
5 & $32(54,14)$ & $17(34,6)$ \\
\hline
\end{tabular}

\section{Cytogenetic studies of medically-irradiated subjects}

Surveys have been made of the chromosome aberrations in lymphocytes from radiotherapy patients. Data from these studies provide a valuable source of information on the relationship between dose and aberration yield, and avoid the need for many animal experiments. The interpretation of aberrations resulting from internal radionuclides is difficult and requires much more study. This is an area where patient data are especially useful and in this section it is proposed to describe two surveys undertaken by the laboratory in cooperation with several medical centres.

One form of treatment for rheumatoid joints is the intra-articular injection of radiogold or radioyttrium. A survey was carried out on 70 patients receiving this treatment to the knees (Stevenson et al., 1973). In the majority of patients only a small aberration yield was found but in a few a large amount of damage was observed, the highest being 28 dicentrics per hundred cells. From the in vitro calibration curves this high yield corresponds to an equivalent whole body dose of about 250 rads but such a dose is not possible from the amount of radionuclide initially injected. Typically the injection was $10 \mathrm{mCi}$ of gold 198 or $5 \mathrm{mCi}$ of yttrium 90 which, when spread uniformly throughout the body, would give a dose of just over 10 rads.

These high aberration yields were found to correlate with the amount of radiogold leaking from the joint and passing along the lymphatic ducts to the inguinal lymph nodes where it could be measured by scintillation scanning techniques. This correlation led Stevenson et al. to suggest that the high aberration yield was due to selective irradiation of lymphocytes as they passed through the nodes containing the activity. On a quantitative basis the data were consistent with about $50 \mathrm{~g}$ of lymphocytes, presumably $T$ cells, circulating through these regional lymph nodes during the week or so required for most of the isotope to decay and receiving in a single transit a dose of about $\mathbf{4 0 0}$ rads.

As a result of this and subsequent cytogenetic studies the use of gold 198 which has a $\gamma$-radiation component has declined in favour of yttrium 90 and other pure $\beta$-emitters. Studies in which the treated joints were immobilised for a few days after injection have shown markedly less leakage of nuclide and consequently lower aberration yields in lymphocytes. Immobilisation with splints or casts and confinement to bed for about three days is now routine practice in some centres.

In 1961 Pochin drew attention to the increased incidence of leukaemia in a group of about 200 patients treated for thyroid cancer with iodine 131 . 
These excess leukaemias, which were noted in the 20 years following treatment, can be associated with whole body radiation doses from the radioiodine. Thus in order to assess the risk of leukaemia it is important to make a reliable estimate of the total body dose involved in the treatment. Although the metabolism of iodine in humans is reasonably well understood the calculation of whole body radiation dose still presents problems. Therefore it was decided to make biological estimates of the equivalent whole body doses by chromosome aberration analysis and to compare these with physical estimates in a number of patients given $80 \mathrm{mCi}$ of iodine 131 for thyroid ablation or $200 \mathrm{mCi}$ for treatment of metastatic deposits following ablation (Lloyd et al., 1976b). Good agreement between the estimates was observed in patients whose thyroid gland had previously been ablated with radioiodine. In patients who had varying degrees of thyroid function the cytogenetic estimate of dose was always considerably higher. It seems probable that the biological estimate was elevated by the selective $\beta$-irradiation of lymphocytes as they passed close to deposits of organically bound iodine retained in the thyroid and liver.

\section{Problems in interpreting aberration yields in terms of dose}

For cases of exposure to external radiation the dose estimates from chromosome aberration analysis are expressed as equivalent whole body doses which are suitable for inclusion in the existing records of dose from film badges. However in practice few accidental irradiations are to the whole body; partial body exposures are much more likely and by the time a blood sample is taken lymphocytes which were in the exposed field have been thoroughly mixed by the circulation with the unirradiated fraction. Unless the localised skin dose is above the erythema threshold ( $\sim 600$ rads) there is no biological technique which can give information about which areas of the body have been irradiated.

It should be possible to take samples of skin from various parts of the body and analyse fibroblast cultures for chromosome damage but many cells containing unstable aberrations would be selectively eliminated in the divisions which take place in culture. In principle differentially stained chromosomes could be examined for stable aberrations such as translocations. However, this is very timeconsuming and must await the development of automation-assisted karyotyping by pattern recognition.

Limited information on partial body exposures can be obtained by studying the distribution of aberrations among the lymphocytes scored. After a uni- form exposure the aberrations are distributed randomly according to Poisson statistics. With a partial body irradiation this random selection breaks down and aberrations are distributed among fewer cells than expected because at the time of the exposure many cells were not in the radiation field. From a careful examination of the distribution of aberrations it might be possible to estimate the fraction of the body irradiated and the dose received, but of course it would not be possible to determine which part of the body was involved. In order to reduce the errors on such an analysis it would be necessary to examine far more than the usual 500 cells, especially at low doses, and so this technique must also await the development of automation in aberration scoring.

Partial body doses from external radiation sources may result from non-penetrating $x$-radiation or $\beta$-particles. With these soft radiations the dose is absorbed within a few millimetres of the body surface so that few lymphocytes are likely to be exposed. In these circumstances cytogenetic dosimetry using lymphocytes is clearly unsuitable but nevertheless in some cases blood samples have been analysed merely to demonstrate that no penetrating radiation was involved and that the equivalent whole body dose was effectively zero.

It might be expected that when a mixture of irradiated and unirradiated lymphocytes is cultured following a partial body exposure, the more highly irradiated cells may be selectively eliminated by death during interphase or that their passage through the first cell cycle in vitro may be delayed. Consequently the cells analysed may not present a true picture of the relative numbers of damaged and undamaged lymphocytes in the peripheral blood and this could lead to an underestimate of dose. Experiments have been carried out in vitro to simulate partial body exposures by culturing mixtures of equal volumes of irradiated and unirradiated blood from the same donors (Lloyd et al., 1973b and 1977a). This has confirmed that irradiated cells are at a selective disadvantage and that most of the cell loss is due to death rather than mitotic delay. However at doses up to 50 rads, which includes the vast majority of accidents, the effect on the aberration yield is negligible. These in vitro data are supported by in vivo experiments in which pigs were given partial body doses of radiation (McFee, 1977). Radiation-induced mitotic delay even at 400 rads is only of the order of a few hours and the human in vitro experiments showed that cell selection did not distort the aberration yield sufficiently to warrant culture times in excess of the standard 48 hours.

Physical factors which could complicate the interpretation of aberration yields are the dose rate or the fractionated nature of an exposure. The attenuation 
of the dose by the body, and the mixing of the lymphocytes by the circulation, result in the exposure of cells to a spectrum of dose rates. Therefore the effective dose rate could be taken as that at the mean mid-line. In practice however dose rate or fractionation need only be considered in accidents where the dose exceeds about 50 rads of low LET radiation because below this level the aberrations are induced by single ionising tracks (the $\alpha \mathrm{D}$ term in the yield equation), and are independent of dose rate. For higher doses, such as 500 rads, experiments have shown that increasing the dose rate increases the aberration yield but this trend ceases at about 150 rads per hour (Purrott and Reeder, 1976). For high LET radiation, fission neutrons for example, the dose rate effect is negligible at all dose levels (Lloyd et al., 1976a).

The incidence of unstable aberrations, particularly the dicentric, in persons who have not been exposed occupationally is low and this is clearly an advantage for cytogenetic dosimetry. However there is no way of being certain that the aberrations seen in any particular case resulted from the recent radiation exposure incident which prompted the analysis. Because of the longevity of lymphocytes, occupational exposure during the previous few years may have contributed to the aberrations seen. Thus it is necessary to consult the records for any previously accumulated dose. A further complication is that any exposure for medical purposes does not feature on the occupational dose record nor is the employee even obliged to inform his employers that he has been exposed to radiation for medical purposes. Such information has to be elicited by the doctor at the time the blood sample is obtained.

Chromosome and, more particularly, chromatid damage may be produced by agents in the environment other than radiation. However, much of this damage has been demonstrated for certain only in vitro, at concentrations well above those experienced by lymphocytes in vivo. Lysergic acid diethylamide (LSD) and caffeine are good examples of drugs which give conflicting in vivo and in vitro results (Dishotsky et al., 1971; Bishun et al., 1973). Shaw (1970) has written a comprehensive review of the chromosomolytic effects of chemicals and Nichols (1970) has reviewed the work on the interaction of viruses with chromosomes.

In general it is considered that viruses act like chemical mutagens in disrupting DNA synthesis, mainly producing chromatid damage which is only expressed as chromosome aberrations of the derived type. Thus previous exposure to many viral or chemical agents does not tend to cause background aberrations conflicting with those induced by radiation in peripheral blood lymphocytes, as these cells remain in $\mathrm{G}_{0}$ until they are stimulated to divide in culture. A few drugs have been shown to produce dicentrics, for example phenylbutazone (Stevenson et al., 1971). However, in general, classified radiation workers are fairly healthy members of the population and are unlikely to have been exposed to such drugs.

\section{Future developments in chromosome aberration} studies

Since the demonstration by Moorhead et al. in 1960 that peripheral blood lymphocytes could be stimulated by PHA to divide in culture, the science of human cytogenetics has advanced rapidly. There is no sign yet that this impetus is waning. The development of several new techniques for staining chromosomes has enabled reliable analysis for stable aberrations to be made. The latest of these tests even permits the accurate identification of exchanges between sister chromatids (Perry and Wolff, 1974). It is now quite clear that routine analysis of chromosome damage can be extended beyond radiation to provide a useful technique for the in vitro and in vivo screening of chemicals which are potentially mutagenic or carcinogenic (Perry and Evans, 1975). Many laboratories are now developing screening programmes based on a variety of biological endpoints including chromosome damage (Bridges, 1976).

In radiobiology the full potential of chromosome aberration induction as an experimental tool has not yet been completely realised. As most of the loss of colony-forming ability in irradiated cell cultures can be accounted for by the presence of visible chromosome aberrations, it is clear that many of the anomalies found in cell survival experiments need to be investigated by cytogenetics.

The technique provides a convenient means of evaluating the distribution of biological damage in radiation beams which have potential value in radiotherapy. For example, Lloyd et al. (1975b) have described an investigation of the characteristics of negative pion beams using chromosome aberration induction in lymphocytes. More recently the technique has been used for examining the biological damage induced around needle sources of californium 252. This isotope emits neutrons and $\gamma$-radiation and has potential application in those treatments where radium needles are currently used (Lloyd et al., in preparation).

The statistical accuracy of any cytogenetic analysis, whether for radiation or chemical effects, depends on the number of cells which are examined. Several laboratories around the world are developing automated computer-linked systems which will locate cells very rapidly on a microscope slide and analyse 
them for karyotypic abnormalities. It is highly likely that during the 1980s such machines will make a major impact on human cytogenetics.

\section{References}

Bishun, N. P., Williams, D. C., and Raven, R. W. (1973). Chromosome damage to HeLa cells grown continuously in caffeine. Mutation Research, 17, 145-146.

Blomgren, H., Wasserman, J., and Littbrand, B. (1974). Blood lymphocytes after radiation therapy of carcinoma of prostate and urinary bladder. Acta Radiologica (Therapy Physics Biology), 13, 357-367.

Bloom, A. D., Neriishi, S., Kamasa, N., Iseki, T., and Keehn, R. J. (1966). Cytogenetic investigations of survivors of the atomic bombings of Hiroshima and Nagasaki. Lancet, 2, 672-674.

Bridges, B. A. (1976). Short-term screening tests for carcinogens. Nature, 261, 195-200.

Buckton, K. E., Langlands, A. O., Smith, P. G., Woodcock, G. E., Looby, P. C., and McLelland, J. (1971). Further studies on chromosome aberration production after whole body irradiation in man. International Journal of Radiation Biology, 19, 369-378.

Buckton, K. E., Smith, P. G., and Court Brown, W. M. (1967). The estimation of lymphocyte lifespan from studies on males treated with $x$-rays for ankylosing spondylitis. In Human Radiation Cytogenetics, pp. 106-114. Edited by H. J. Evans, W. M. Court Brown and A. S. McLean. North Holland: Amsterdam.

Clemenger, J. F., and Scott, D. (1971). In vitro and in vivo sensitivity of cultured blood lymphocytes to radiation induction of chromosome aberrations. Nature New Biology, 234, 154.

Dishotsky, N. I., Loughman, W. D., Mogar, R. E., and Lipscomb, W. R. (1971). LSD and genetic damage. Science, 172, 431-440.

Dolphin, G. W. (1969). Biological dosimetry with particular reference to chromosome aberration analysis. In Handling of Radiation Accidents, pp. 215-224. IAEA-SM-119/4. International Atomic Energy Authority: Vienna.

Dolphin, G. W., Lloyd, D. C., and Purrott, R. J. (1973). Chromosome aberration analysis as a dosimetric technique in radiological protection. Health Physics, 25, 7-15.

Dutrillaux, B., and Lejeune, J. (1971). Sur une nouvelle technique d'analyse du caryotype humain. Comptes rendus hebdomadaires des séances de l'Académie des Sciences de Paris, Série D, 272, 2638-2640.

Giles, N. H. (1954). Radiation-induced chromosome aberrations in Tradescantia. In Radiation Biology, vol. 1, pt. 2, pp. 713-761. Edited by A. Hollaender. McGraw-Hill: London.

Greaves, M. F., Owen, J. J. T., and Raff, M. C. (1974). T and $B$ Lymphocytes. Excerpta Medica: Amsterdam.

Harrison, N. T., Escott, P. C., Dolphin, G. W., Purrott, R. J., Alexander, J. L., and Halnan, K. E. (1974). The investigation and reconstruction of a severe radiation injury to an industrial radiographer in Scotland. In Proceedings 3rd International Congress of the International Radiological Protection Association, 9-14 September 1973, Washington, pp. 760-768, CONF. 790907-P1. Edited by W. S. Snyder. United States Atomic Energy Commission: Oak Ridge.

International Commission on Radiological Protection (1975). Report of the Task Group on Reference Man. ICRP Publication 23. Pergamon Press: Oxford.

Lea, D. E. (1946). Actions of Radiation on Living Cells. Cambridge University Press: London.
Lloyd, D. C., Purrott, R. J., and Dolphin, G. W. (1973a). Chromosome aberration dosimetry in a case of overexposure to radiation. Nature, 241, 69-70.

Lloyd, D. C., Purrott, R. J., and Dolphin, G. W. (1973b). Chromosome aberration dosimetry using human lymphocytes in simulated partial body irradiation. Physics in Medicine and Biology, 18, 421-431.

Lloyd, D. C., Purrott, R. J., Dolphin, G. W., Bolton, D., Edwards, A. A., and Corp, M. J. (1975a). The relationship between chromosome aberrations and low LET radiation dose to human lymphocytes. International Journal of Radiation Biology, 28, 75-90.

Lloyd, D. C., Purrott, R. J., Dolphin, G. W., and Reading, D. H. (1975b). An investigation of the characteristics of a negative pion beam by means of induced chromosome aberrations in human peripheral blood lymphocytes. International Journal of Radiation Biology, 27, 223-236.

Lloyd, D. C., Purrott, R. J., Dolphin, G. W., and Edwards, A. A. (1976a). Cnromosome aberrations induced in human lymphocytes by neutron irradiation. International Journal of Radiation Biology, 29, 169-182.

Lloyd, D. C., Purrott, R. J., Dolphin, G. W., Horton, P. W., Halnan, K. E., Scott, J. S., and Mair, G. (1976b). A comparison of physical and cytogenetic estimates of radiation dose in patients treated with iodine 131 for thyroid carcinoma. International Journal of Radiation Biology, 30, 473-485.

Lloyd, D. C., Dolphin, G. W., Purrott, R. J., and Tipper, P. A. (1977a). The effect of $x$-ray induced mitotic delay on chromosome aberration yields in human lymphocytes. Mutation Research, 42, 401-412.

Lloyd, D. C., Purrott, R. J., Prosser, J. S., Dolphin, G. W., Tipper, P. A., Reeder, E. J., White, C. M., Cooper, S., and Stephenson, B. D. (1977b). Doses in radiation accidents investigated by chromosome aberration analysis. VII. A review of cases investigated: 1976. National Radiological Protection Board Report No. 57. NRPB: Harwell.

Mayall, B. H. (ed) (1976). Proceedings of the 4th Engineering Foundation Conference on Automatic Cytology. Journal of Histochemistry and Cytochemistry, 24, 1-414.

McFee, A. F. (1977). Chromosome aberrations in the leukocytes of pigs after half-body or whole-body irradiation. Mutation Research, 42, 395-400.

Moorhead, P. S., Nowell, P. C., Mellman, W. J., Battips, D. M., and Hungerford, D. A. (1960). Chromosome preparations of leukocytes cultured from human peripheral blood. Experimental Cell Research, 20, 613-616.

Nichols, W. W. (1970). Virus-induced chromosome abnormalities. Annual Review of Microbiology, 24, 479-500.

Norman, A., Sasaki, M. S., Ottoman, R. E., and Fingerhut, A. G. (1966). Elimination of chromosome aberrations from human lymphocytes. Blood, 27, 706-714.

Perry, P., and Evans, H. J. (1975). Cytological detection of mutagen-carcinogen exposure by sister chromatid exchange. Nature, 258, 121-125.

Perry, P., and Wolff, S. (1974). New Giemsa method for the differential staining of sister chromatids. Nature, 251, 156-158.

Pochin, E. E. (1961). The occurrence of leukaemia following radioiodine therapy. In Advances in Thyroid Research, pp. 392-397. Edited by R. Pitt-Rivers. Pergamon Press: London.

Prosser, J. S. (1976). Survival of human T and B lymphocytes after X-irradiation. International Journal of Radiation Biology, 30, 459-465.

Purrott, R. J., and Lloyd, D. C. (1972). The study of chromosome aberration yield in human lymphocytes as an indicator of radiation dose. I. Techniques. National Radiological Protection Board Report No. 2. NRPB: Harwell. 
Purrott, R. J., Dolphin, G. W., Lloyd, D. C., Rickard, B., and Eltham, E. (1972). The study of chromosome aberration yield in human lymphocytes as an indicator of radiation dose. II. A review of cases investigated: 1970-71. National Radiological Protection Board Report No. 5. NRPB: Harwell.

Purrott, R. J., Lloyd, D. C., Dolphin, G. W., Eltham, E. J., Platt, S. K., Tipper, P. A., and Strange, C. M. (1973). The study of chromosome aberration yield in human lymphocytes as an indicator of radiation dose. III. A review of cases investigated: 1971-72. National Radiological Protection Board Report No. 10. NRPB: Harwell.

Purrott, R. J., Lloyd, D. C., Prosser, J. S., Dolphin, G. W., Eltham, E. J., Tipper, P. A., White, C. M., and Cooper, S. J. (1974). The study of chromosome aberration yield in human lymphocytes as an indicator of radiation dose. IV.A review of cases investigated: 1973. National Radiological Protection Board Report No. 23. NRPB: Harwell.

Purrott, R. J., Lloyd, D. C., Prosser, J. S., Dolphin, G. W., Tipper, P. A., Reeder, E. J., White, C. M., Cooper, S. J., and Stephenson, B. D. (1975). The study of chromosome aberration yield in human lymphocytes as an indicator of radiation dose. V. A review of cases investigated: 1974. National Radiological Protection Board Report No. 35. NRPB: Harwell.

Purrott, R. J., Lloyd, D. C., Prosser, J. S., Dolphin, G. W., Tipper, P. A., Reeder, E. J., White, C. M., Cooper, S. J., and Stephenson, B. D. (1976). The study of chromosome aberration yield in human lymphocytes as an indicator of radiation dose. VI. A review of cases investigated: 1975. National Radiological Protection Board Report No. 41. NRPB: Harwell.

Purrott, R. J., and Reeder, E. (1976). The effect of changes in dose rate on the yield of chromosome aberrations in human lymphocytes exposed to gamma radiation. Mutation Research, 35, 437-444.

Savage, J. R. K. (1976). Classification and relationships of induced chromosomal structural changes. Journal of Medical Genetics, 12, 103-122.

Sax, K. (1938). Chromosome aberrations induced by $x$-rays. Genetics, 23, 494-516.

Sharpe, H. B. A., Dolphin, G. W., Dawson, K. B., and Field, E. O. (1968). Methods for computing lymphocyte kinetics in man by analysis of chromosomal aberrations sustained during extracorporeal irradiation of the blood. Cell and Tissue Kinetics, 1, 263-271.

Shaw, M. W. (1970). Human chromosome damage by chemical agents. Annual Review of Medicine, 21, 409-432.

Stevenson, A. C., Bedford, J., Dolphin, G. W., Purrott, R. J., Lloyd, D. C., Hill, A. G. S., Hill, H. F. H., Gumpel, J. M., Williams, D., Scott, J. T., Ramsay, N. W., Bruckner, F. E., and Fearn, C. B. D'A. (1973). Cytogenetic and scanning study of patients receiving intra-articular injections of gold 198 and yttrium 90. Annals of the Rheumatic Diseases, 32, 112-123.

Stevenson, A. C., Bedford, J., Hill, A. G. S., and Hill, H. F. H. (1971). Chromosomal studies in patients taking phenylbutazone. Annals of the Rheumatic Diseases, 30, 487-500.

Sumner, A. T. (1972). A simple technique for demonstrating centromeric heterochromatin. Experimental Cell Research, 75, 304-306.

Sumner, A. T., Evans, H. J., and Buckland, R. A. (1971). A new technique for distinguishing between human chromosomes. Nature New Biology, 232, 31-32.

Vodopick, H., and Andrews, G. A. (1974). Accidental radiation exposure. Archives of Environmental Health, 28, 53-56. 